\title{
Resetting priorities in precision medicine - The role of social prescribing
}

Short title: Social prescribing for precision medicine

Erica Pitini ${ }^{1}$, Giovanna Adamo ${ }^{1}$, Muir Gray ${ }^{2}$ and Anant Jani ${ }^{2 *}$

1.Sapienza University of Rome, Department of Public Health and Infectious Diseases Rome, Lazio,

IT

2. University of Oxford, Value Based Healthcare Programme - Dept of Primary Care Radcliffe Primary Care Building, Radcliffe Observatory Quarter, Woodstock Rd, Oxford, Oxfordshire, UK OX2 $6 G G$

*Correspondences should be addressed to anant.jani@phc.ox.ac.uk

Declaration of conflicting interests: The Authors declare that there are no conflicts of interest.

Funding: This research received no specific grant from any funding agency in the public, commercial, or not-for-profit sectors.

Guarantor: Anant Jani is the Guarantor for the article.

Contributorship statement: Erica Pitini and Anant Jani were involved in the design and writing of the mansucript; Giovanna Adamo and Muir Gray were involved in writing the manuscript. 


\section{Precision Medicine: Genes, Lifestyle, Environment}

"Precision medicine", a comprehensive approach to healthcare, is finally catching on. By definition, precision medicine aims to bridge the gap between the nature vs. nurture debate and tailor treatment and prevention strategies to individuals or groups based on variations in genes, environment and lifestyle. This is opposed to the one-size-fits-all approach in which interventions are developed for the average person and everyone receives the same care. ${ }^{1}$ Precision medicine seems, therefore, to be the key for all healthcare professionals, particularly those in primary care, to better understand and face the intricacy underlying health and disease. This comprehensive approach is expected to lead future clinical practice, health care delivery, and research, particularly in the field of Common Complex Disorders (CCD) where addressing the complex interactions between genes, lifestyle, and environment is a major challenge.

\section{The hijacking of precision medicine toward genomics}

While the above happens in theory, in practice, precision medicine has been, and still is, widely seen as an approach centered on individualized genomic information. Searching for "Precision Medicine" on PubMed yields hundreds of titles about genetic mutations, genomic sequencing, molecular profiling, pharmacogenomics, etc. The same happens in the realms of research investment, scientific community interest and public enthusiasm ${ }^{2}$ : genetics and genomics rarely share the precision medicine stage with lifestyle and environment. 
Some genetic and genomics applications, like pharmacogenomics to study individual responses to cancer drugs or cancer genetic screening programs, are effective and cost-effective and can have a significant impact on both clinical and public health practice ${ }^{3}$. Nevertheless, the hijacking of precision medicine towards only genomic medicine limits our ability to positively impact health. For example, other leading determinants of health (i.e. social circumstances, environmental exposure, behavioral choices) are known to interact with genes in a way that influences health outcomes:

"Whether a gene is expressed can be determined by environmental exposures or behavioral patterns. The nature and consequences of behavioral choices are affected by our social circumstances. Our genetic predispositions affect the health care we need, and our social circumstances affect the health care we receive." ${ }^{4}$

Furthermore, even though technological advances are lowering the costs of genomic technologies, making genomic medicine available to the entire population that might need it would still be costprohibitive, which is a major challenge to widespread implementation of genomic medicine. To maximize the impact of finite resources, investments should concentrate on interventions able to ensure the maximum benefit to the maximum number of people. Expensive genomic technologies have the potential to exacerbate healthcare disparities and embed inequalities because they could divert resources from health priorities such as cigarette smoking, physical inactivity, poor diet and alcohol use that disproportionately disadvantage those with the lowest socio-economic status and greatest healthcare need. ${ }^{5}$ 
Only focusing on the genomic medicine component of precision medicine will never solve our main public health problems i.e. reducing the burden of CCDs, reducing healthcare disparities and rationalizing finite budgets. We must reset priorities in precision medicine recognizing that costeffective health promotion interventions addressing behavioural and environmental factors such as smoking, diet, physical activity, housing and outdoor air quality can benefit everyone, irrespective of their genomic profile. A further step would be considering the social circumstances affecting environment and behaviors, i.e. "the conditions in which people are born, grow, work, live, and age, and the wider set of forces and systems shaping the conditions of daily life" ${ }^{6} \mathrm{~A}$ holistic precision medicine approach focused not only on genomics but also on lifestyle, environment and more broadly on the social determinants of health would be the best way to reduce healthcare demand, health disparities and healthcare costs.

\section{Social prescribing: A balancing force for precision medicine}

Addressing the wider determinants of health is not easy. Beyond the need for public policies aimed at addressing socioeconomic factors on a large scale, what can be done in every day clinical practice? How can healthcare professionals address the social needs of their community?

A set of solutions that is taking hold is contained within the umbrella of social prescribing, which helps healthcare professionals to manage a person's social needs by linking traditional clinical practice with non-medical activities and services within the community. ${ }^{7}$ Social prescribing referrals are usually made by General Practitioners (GPs), but other frontline healthcare professionals may also be involved e.g. those working in cancer services. The referral may be 
direct or mediated by a link worker who helps co-design personalized social prescriptions that are provided by local voluntary or community organizations or statutory sector services. ${ }^{8}$

Though the evidence base on the effectiveness and cost-effectiveness of social prescriptions (social px) is limited because of methodological weakness in study design and reporting, ${ }^{9}$ the evidence that does exist for social px points to a promising role for them to address multiple aspects of the precision medicine paradigm, particularly lifestyle and environmental factors, as highlighted below.

\section{Lifestyle}

Lifestyle is the easiest precision medicine component that can be addressed with social px.

Lifestyle risks factors are easily modifiable compared to environmental and genetic factors. There are many examples of social px supporting management and prevention of chronic conditions through healthy living initiatives, e.g. healthy eating, physical activity and smoking cessation. Examples include exercise prescriptions, where patients are referred to supported exercise programmes such as cycling, guided healthy walks, dance classes and team sports; and green activities prescriptions, such as gardening, horticulture, and walking in parks. The benefits of these prescriptions go far beyond the expected physical health improvements and cardiovascular diseases prevention. They allow people to learn new skills; structure their day; improve selfesteem, mood, socialization and cognitive functioning, and thus also address mental health and general wellbeing. ${ }^{10}$ Moreover, specific social px have been developed to address non-classical 
lifestyle needs through initiatives such as arts on prescription, i.e. creative activities such as drama, film, music, painting and photography; and books on prescription. ${ }^{10}$

\section{Environment}

"In [...] Tower Hamlets one in eight children starting primary school are obese, and that doubles to more than one in four when they leave, at age $11[\ldots]$ There are all sorts of reasons why people become obese, but the 42 chicken shops per secondary school in the borough are definitely among them."11

Environmental factors are more difficult to address when compared to lifestyle factors but there are still several approaches that can be used to address environmental factors (Table 1):

Table 1. Social prescriptions that can address environmental factor impacting health.

\begin{tabular}{|c|c|c|c|}
\hline Approach & Description & Timeframe to impact & Example \\
\hline Tactical & $\begin{array}{l}\text { Account for the } \\
\text { environment }\end{array}$ & Short term & $\begin{array}{l}\text { GPs and teachers know the presence } \\
\text { of fried chicken shops will influence } \\
\text { children's eating habits. In response } \\
\text { to this, GPs and/or teachers can } \\
\text { prescribe access to cooking and } \\
\text { education classes so children and } \\
\text { parents can be educated about } \\
\text { nutrition and making better and } \\
\text { healthier dietary choices. }\end{array}$ \\
\hline Operational & $\begin{array}{l}\text { Adapt the } \\
\text { environment }\end{array}$ & Short-Medium term & $\begin{array}{l}\text { GPs, teachers and local authorities } \\
\text { work with the fried chicken shops to } \\
\text { ensure healthier options are provided } \\
\text { to children. Local authorities could } \\
\text { give a social px to the fried chicken } \\
\text { shop to work local voluntary and } \\
\text { community organsiations who could } \\
\text { help them create healthy meals that } \\
\text { would appeal to children and would } \\
\text { also ensure their business is not } \\
\text { negatively affected. }\end{array}$ \\
\hline
\end{tabular}


Strategic Change the Medium-Long term Parents, children, teachers, local environment authorities, GPs and other local, regional and national stakeholders could come together to change policies on the types of food that could be provided close to schools. National public bodies could attach subsidies to these policies, which could then be delivered as a social prescription locally and regionally to ensure healthier meal options are always available for children near their schools.

Initiatives at each of these levels may seem outside of the realm of social px as they are currently conceptualized, but we would argue that as a community we need to make a shift in our thinking because these are important factors that must be addressed to improve health of individuals and populations. Indeed, initiatives have been used to reduce or remove (e.g. general public health measures like the 1848 Public Health Act, ${ }^{12}$ clean air regulations like the Clean Air Act of $1956^{13}$ or the more recent Health Act 2006 which banned public smoking ${ }^{14}$ ) the impact of environmental factors, but their use is inconsistent. Andermann suggests facilitators like training and toolkits, such as CLEAR (Community Links Evidence to Action Research), can help clinicians successfully address environmental factors in practice. ${ }^{15}$ To address strategic issues, public health and policy professionals must come together to actively understand, design and implement initiatives to tackle environmental factors negatively affecting health at a population level.

\section{Genetics}

When looking at the third component of precision medicine, namely genes, a key consideration is whether genomic information can actually be used to change unhealthy behaviors. 
"As the science develops, it is increasingly possible to provide information about multiple single genes, each relating to different disease risks, and also to aggregate multiple risk loci and identify patterns of characteristics across multiple genes that in combination confer increased risks of one or more diseases. However, DNA based disease risk estimates will only translate into health benefits if acting on them modifies disease outcomes, and if those informed of these genetic risks undertake the relevant actions." 16

Evidence so far suggest that communicating genetic-based risk estimates has no apparent effect on risk-reducing health behaviors and motivation to engage in such behaviors. ${ }^{16}$ Nevertheless, this might change if genomic information would be supplemented with social px. Thus, people known to be genetically predisposed to diabetes, cancer or heart disease could be offered effective behavior change interventions through social px, hopefully reducing their chance of disease.

\section{Quo vadis?}

To reach the broad public health goals of improving population health and reducing healthcare disparities, in the context of finite resources, it is necessary to support a comprehensive precision medicine approach where research and interventions on genes, environment and lifestyle can work in synergy. While genomics is already under the spotlight, social px may be a valuable option to integrate behavioral and environmental factors in a holistic model of care because they can bring social determinants of health into clinical practice, which, when integrated with genomics information, can deliver true precision medicine. 
To make true precision medicine a reality, appropriate delivery models for its provision need to be tested and identified. One of the most promising homes for precision medicine is primary care because general practitioners are the first in line to manage the crucial genetic, behavioral and environmental factors affecting the health status of their patients. Precision medicine should, therefore, be the central approach for primary care.

This transformation of primary care faces many challenges and primary care professionals will require new competencies to deal with them. First, they should be able to assess each individual's biological and social background, understand how they influence the individual's health status and use this information to provide tailored interventions. Moreover, they should learn how to coordinate the collaboration between individuals, families, community, government, other levels of care (i.e specialist care, screening programmes, etc.) and all the other sectors needed to provide comprehensive care. Finally, they will need additional infrastructural support, particularly for data collection, storage and sharing.

Such an approach would also be a driver to the provision of internationally advocated patientcentred care and, further, people-centered care:

"People-centered care is care that is focused and organized around the health needs and expectations of people and communities, rather than on diseases. Whereas patient-centred care is commonly understood as focusing on the individual seeking care (the patient), people-centred care encompasses these clinical encounters and also includes attention to the health of people in their communities and their crucial role in shaping health policy and health services." ${ }^{17}$ 


\section{References}

1. National Institute of Health - U.S. national Library of Medicine. What is precision medicine?, https://ghr.nlm.nih.gov/primer/precisionmedicine/definition (2015, accessed 20 June 2019).

2. Joyner MJ, Paneth N, loannidis JP. What Happens When Underperforming Big Ideas in Research Become Entrenched? AMA 2016;316:1355-1356.

3. Centers for Disease Control and prevention. Public Health Genomics and Precision Health Knowledge Base (v5.7),

https://phgkb.cdc.gov/PHGKB/topicFinder.action;jsessionid=B1A90B193E571501EDDDD335B63679 9F?Mysubmit=init\&query=tier+1 (2018, accessed 20 June 2019).

4. McGinnis JM, Williams-Russo P, Knickman JR. The case for more active policy attention to health promotion. Health Aff (Millwood) 2002;21:78-93.

5. James JE. Personalised medicine, disease prevention, and the inverse care law: more harm than benefit? Eur J Epidemiol 2014;29:383-90.

6. World Health Organization. Social determinants of health, https://www.who.int/social determinants/en/(accessed 20 June 2019).

7. Drinkwater C, Wildman J, Moffatt S. Social prescribing. BMJ 2019;364:11285.

8. Polley MJ, Fleming J, Anfilogoff T, et al. Making Sense of Social Prescribing. Report, University of Westminster, UK, August 2017.

9. Bickerdike L, Booth A, Wilson PM, et al. Social prescribing: less rhetoric and more reality. A systematic review of the evidence. BMJ Open 2017;7:e013384.

10. Thomson L, Camic PM, Chatterjee HJ. A Review of Community Referral Schemes. Report, University College London, UK, 2015. 
11. Boseley S. The chicken shop mile and how Britain got fat. The Guardian, 28 January 2016, https://www.theguardian.com/society/2016/jan/28/chicken-shop-mile-britain-fat-cheap-foodobesity.

12. UK Parliament. The 1848 Public Health Act, https://www.parliament.uk/about/livingheritage/transformingsociety/towncountry/towns/tyne-and-wear-case-study/about-thegroup/public-administration/the-1848-public-health-act/ (accessed 28 January 2020).

13. UK Legislation. Clean Air Act 1956, http://www.legislation.gov.uk/ukpga/Eliz2/4-5/52/enacted (accessed 28 January 2020).

14. UK Legislation. Health Act 2006, http://www.legislation.gov.uk/ukpga/2006/28/contents (accessed 28 January 2020).

15. Andermann A. Taking action on the social determinants of health in clinical practice: a framework for health professionals. CMAJ 2016; 188: E474-E483.

16. Hollands GJ, French DP, Griffin SJ, et al. The impact of communicating genetic risks of disease on risk-reducing health behaviour: systematic review with meta-analysis. BMJ 2016;352:i1102.

17. World Health Organization. Health systems delivery, https://www.who.int/healthsystems/topics/delivery/en/ (accessed 20 June 2019). 